\title{
Glucocorticoids for treating Takotsubo syndrome?
}

\author{
Josef Finsterer $^{1} \cdot$ Claudia Stöllberger $^{2}$
}

Received: 17 February 2016/Accepted: 17 February 2016/Published online: 4 March 2016

(C) Springer-Verlag Berlin Heidelberg 2016

We have the following comments concerning Venkatraman's article about a 27-year-old African-American male with recovery from Takotsubo syndrome (TTS) during acute disseminated encephalomyelitis (ADEM) under methyl-prednisolone [1].

We do not agree with the diagnosis ADEM. First, the "A" in ADEM stands for "acute", but neurological manifestations were present for at least 3 months [1]. Second, ADEM is usually preceded by acute infectious disease [2], but none is reported [1]. Third, the patient is described with "no significant past medical history", but is obviously polytoxicomanic (cannabinoids, opiates). Did he inject heroin? Was he HIV positive? Were parasitological infestations (eosinophilia?), multiple sclerosis (visually evoked potentials?), and antiphospholipid antibody syndrome excluded? Fourth, the brainstem lesion was still present after 2 weeks.

Why "atypical" TTS? The patient had the global TTS type, which usually has a poor prognosis [3]. Atypical is that he recovered without cardiac therapy. Was the right ventricle involved?
Overall, this interesting case requires long-term followup, exclusion of further differentials, and a thoroughly taken previous history.

\section{Compliance with ethical standards}

Conflict of interest There are no conflicts of interest.

\section{References}

1. Venkatraman A, Bajaj NS, Khawaja A, Meador W (2016) Cardiogenic shock from atypical Takotsubo cardiomyopathy attributed to acute disseminated encephalomyelitis lesion involving the medulla. Clin Auton Res (in press)

2. Höllinger P, Sturzenegger M, Mathis J, Schroth G, Hess CW (2002) Acute disseminated encephalomyelitis in adults: a reappraisal of clinical, CSF, EEG, and MRI findings. J Neurol 249:320-329

3. Finocchiaro G, Kobayashi Y, Magavern E, Zhou JQ, Ashley E, Sinagra G, Schnittger I, Knowles JW, Fearon WF, Haddad F, Tremmel JA (2015) Prevalence and prognostic role of right ventricular involvement in stress-induced cardiomyopathy. J Card Fail 21:419-425
Josef Finsterer

fipaps@yahoo.de

1 Krankenanstalt Rudolfstiftung, Postfach 20, 1180 Vienna, Austria, Europe

2 2nd Medical Department with Cardiology and Intensive Care Medicine, Krankenanstalt Rudolfstiftung, Vienna, Austria 